\section{Autosomal recessive hypotrichosis simplex with woolly hair: a report of a new family}

\author{
Khalid Al Aboud, ${ }^{1}$ Daifullah Al Aboud ${ }^{2}$ \\ 'Dermatology Department, King Faisal \\ Hospital, Makkah; ${ }^{2}$ Dermatology \\ Department, Taif University, Taif, \\ Saudi Arabia
}

\begin{abstract}
Autosomal recessive hypotrichosis simplex with woolly hair is a rare dermatological disorder, characterized by sparse hair and tightly curled hair. We report on a new family affected with this disorder which has not previously been reported. In this family, 2 siblings were affected. We believe that the disorder is not rare, but is possibly misdiagnosed, and hence underreported.
\end{abstract}

\section{Case Report}

Two females out of 8 siblings of a Saudi family presented with progressive hair loss which had started from early childhood. The family pedigree is shown in Figure 1. Both patients have tightly curled hair which, at birth, covered the whole scalp. The hair never grew long. Neither girl has ever had her hair cut. On examination, in both cases the hair on the scalp was very sparse and curled (Figure 2). They had non-consanguineous parents. The father, who had died a few years before, had been the only member of the family who had curled hair. However, there was no record of his hair having thinned. But the family also mentioned that one of the grandmothers of the father had been bald, but they could not provide further details regarding the cause of her baldness.

\section{Introduction}

The 2 girls were 24 and 16 years old. Their hair loss had started a few years after birth. Apart from one ancestor on the father's side who had had a history of hair thinning, there was no family history of a similar condition and no significant past medical history. On examination, both patients had curled hair and diffuse thinning of scalp hair. Both cases were diagnosed on different occasions as cases of telogen effluvium and diffuse alopecia areata. The younger patient reported an improvement in hair loss after using minoxidil $2 \%$ spray on her scalp. Eyebrows, eyelashes, and pubic and body hair were all normal in both patients. Axillary hair was sparse in both patients, and also in the mother. There was no sign of ectodermal dysplasia and there were no abnormalities observed in the skin, nails, teeth or eyes. No hair abnormalities were detected in the mother or the other siblings. Hair obtained by pulling strands from the scalps of both patients was examined by light microscope and no structural abnormalities were found. Punch skin biopsies $(4 \mathrm{~mm}$ ) were obtained from the occiput of the 2 girls and their mother, and were cut by horizontal section. Examination of the specimens revealed the presence of a hair follicle and normal follicular units. Follicular units are the lobules that result from the merging together of many hair follicles at the level of the infundibulum; each follicular unit contains an average of three to five hair follicles. No inflammatory infiltrates were seen and sebaceous glands were normal. Based on the clinical findings and family history, we diagnosed the condition as autosomal recessive hypotrichosis simplex (ARHS) with woolly hair, and the nature of the disease was explained to the patients. There is no available treatment for the disease.

\section{Discussion}

Hereditary hypotrichosis refers to a state where an individual's hair density is less than normal due to genetic factors. ${ }^{1-18}$ It may be the only abnormality in some cases or it may occur in association with other conditions, such as chromosomal abnormalities or ectodermal dysplasias. ${ }^{6}$ At least four autosomal dominant and six autosomal recessive forms of hypotrichosis have been described. All these ten forms of hypotrichosis have been mapped on different human chromosomes and in most of these cases the corresponding genes have been identified. $^{3}$

Online Mendelian Inheritance in Man (OMIM) is an online database of human genes and genetic disorders, available from http://www. ncbi.nlm.nih.gov/omim. It includes many entries for conditions characterized by hypotrichosis from which we have selected the following disorders which can be included in the differential diagnosis for the family presented.

Hereditary hypotrichosis simplex of scalp (HHSS) (OMIM 146520) is a hereditary hypotrichosis that is limited to the scalp with no other associated physical or mental abnormalities. It is a form of non-syndromic inherited hair loss disorder, which has marked genet-
Correspondence: Khalid Al Aboud,

P.0 Box 5440, Makkah 21955, Saudi Arabia.

E-mail: amoa65@hotmail.com

Key words: alopecia, hair, hypotrichosis.

Received for publication: 31 May 2011.

Accepted for publication: 20 July 2011.

This work is licensed under a Creative Commons Attribution NonCommercial 3.0 License (CC BYNC 3.0).

(C) Copyright K. Al Aboud and D. Al Aboud, 2011 Licensee PAGEPress, Italy

Dermatology Reports 2011; 3:e13

doi:10.4081/dr.2011.e13

ic and clinical heterogeneity. A decrease in the number of the hair follicles and non-inflammatory alopecia are the pathological hallmarks of hereditary hypotrichosis simplex. ${ }^{9,10}$ The disorder is characterized by progressive hair loss from the scalp, beginning in the middle of the first decade, and reaching to almost complete baldness by 30 years of age. ${ }^{7}$ It was first described by Toribio and Quinones in 1974, and there have been many subsequent reports. ${ }^{8-14}$ We and other colleagues reported HHSS for the first time in Saudi Arabia in 2002 in a family in Taif. ${ }^{2}$ We also added 2 additional families affected with this disorder from Makkah. ${ }^{3}$ Makkah and Taif are two cities near

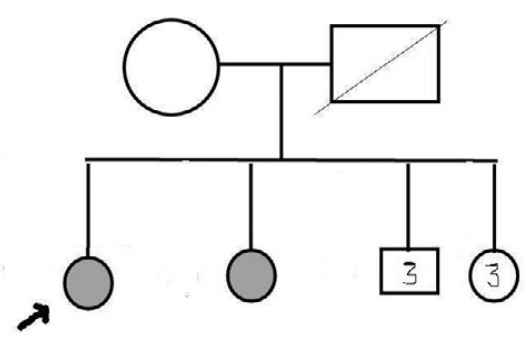

Figure 1. Family pedigree. Shaded circles represent the affected members.

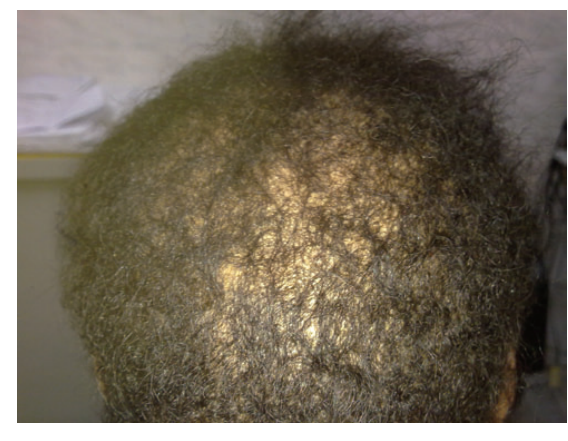

Figure 2. Hypotrichosis in the second patient. 
to each other in the western province of Saudi Arabia. The family in this report also lives in Makkah. None of the families reported are related to each other, but they might belong to a large Arabian tribe living in the western province of Saudi Arabia.

However, there are cases in which the hypotrichosis is not limited to the scalp; those cases are best referred to as hereditary hypotrichosis simplex. ${ }^{15,16}$ Similarly, there are reports of autosomal recessive hypotrichosis simplex (ARHS) with or without woolly hair (OMIM ID \#604379). This is a hereditary hair disorder which is characterized by tightly curled hair and is associated with sparse hair. It can be caused by mutations in the $P 2 R Y 5$ or lipase $H(L I P H)$ genes. Disruption of either gene results in phenotypes with features of both woolly hair (WH) and hypotrichosis. ${ }^{4}$ The family in this report has the clinical features of ARHS with woolly hair.

Congenital woolly hair can also occur alone. It is a disorder with structural defects of the hair shafts. The clinical features occur at birth, with hair over the entire scalp region being coarse, lusterless, dry, and tightly curled, leading to a diffuse woolly hair phenotype with normal hair density. The hair grows slowly and stops growing once it is a few inches long. Some cases of woolly hair are associated with systemic or other skin diseases. Congenital woolly hair without any associated disorder is inherited in an autosomal dominant (OMIM ID\#194300) or autosomal recessive manner (OMIM ID \#278150). Recently, mutations in the $P 2 R Y 5$ gene, encoding a G-protein coupled receptor, have been shown to be responsible for autosomal recessive woolly hair. ${ }^{19}$ It is interesting to note that, according to the family members, the father had only had woolly hair without hypotrichosis, although we cannot verify this as the father has died.

Marie Unna hereditary hypotrichosis (MUHH) (OMIM ID \#146550) is another condition, which might be considered in the differ- ential diagnoses of this family. It is an autosomal dominant form of isolated alopecia which is characterized by the absence or scarcity of scalp hair, eyebrows and eyelashes at birth. Coarse wiry hair begins to grow during childhood, but this is followed by progressive hair loss which usually begins around puberty. ${ }^{6}$

We believe that ARHS with woolly hair is not rare, but is possibly misdiagnosed, and hence underreported.

\section{References}

1. Basit S, Ali G, Wasif N, et al. Hum Genet 2010;128:213-20.

2. Al Aboud K, Al Hawsawi K, Al Aboud D, Al Githami A. Hereditary hypotrichosis simplex: report of a family. Clin Exp Dermatol 2002;27:654-6.

3. Al Aboud D, Al Aboud K, Al Hawsawi K, Al Aboud A. Hereditary hypotrichosis simplex of the scalp: a report of 2 additional families. Sudan J Dermatol 2005;3:128-31.

4. Shimomura Y, Wajid M, Zlotogorski A, et al. Founder mutations in the lipase $h$ gene in families with autosomal recessive woolly hair/hypotrichosis. J Invest Dermatol 2009;129:1927-34.

5. Pasternack SM, Murugusundram S, Eigelshoven $\mathrm{S}$, et al. Novel mutations in the P2RY5 gene in one Turkish and two Indian patients presenting with hypotrichosis and woolly hair. Arch Dermatol Res 2009;301:621-4.

6. de Berker DAR. Congenital hypotrichosis. Int J Dermatol 1999;38:25-33.

7. Toribio J, Quinones PA. Hereditary hypotrichosis simplex of the scalp: evidence for autosomal dominant inheritance. Br J Dermatol 1974;91:687-96.

8. Khon G, Metzker A. Hereditary hypotrichosis simplex of the scalp. Clin Genet 1987;2:120-4.
9. Hess R0, Uno H. Hereditary hypotrichosis of the scalp. Am J Med Genet 1991;39:1259.

10. Ibsen HH, Clemmensen OJ, Brandrup F. Familial hypotrichosis of the scalp. Autosomal dominant inheritance in four generations. Acta Derm Venereol 1991;7: 349-51.

11. Rodriguez Diaz E, Fernandez Blasco G, Martin Pascual A, Armijo M. Hereditary hypotrichosis simplex of the scalp. Dermatology 1995;191:139-41.

12. Just M, Ribera M, Fuente MJ, et al. Hereditary hypotrichosis simplex. Dermatology 1998;196:339-42.

13. Cambiaghi S, Barbareschi M. A sporadic case of congenital hypotrichosis simplex of the scalp: difficulties in diagnosis and classification. Pediatr Dermatol 1999;16: 301-4.

14. Betz RC, Lee YA, Bygum A, et al. A gene for hypotrichosis simplex of the scalp maps to chromosome 6p21.3. Am J Hum Genet 2000;66:1979-83.

15. Bentley-Phillips B, Grace HJ. Hereditary hypotrichosis: a previously undescribed syndrome. Br J Dermatol 1979;101:331-9.

16. Baumer A, Belli S, Trueb RM, Schinzel A. An autosomal dominant form of hereditary hypotrichosis simplex maps to 18p11.32 p11.23 in an Italian family. Eur J Hum Genet 2000;8:443-8.

17. Ahmad M, Abbas H, Haque S. Alopecia universalis as a single abnormality in an inbred Pakistani kindred. Am J Med Genet 1993;46:369-71.

18. Ahmed W, Irvine $\mathrm{AD}$, Lam $\mathrm{H}$, et al. Missense mutation in the zinc-finger domain of the human hairless gene underlies congenital atrichia in a family of Irish travellers. Am J Hum Genet 1998;63:98491.

19. Nakamura M, Tokura Y. Congenital woolly hair without P2RY5 mutation. Dermatoendocrinol 2009;1:58-9. 